\title{
THE CORNEAL SECTION IN CATARACT EXTRACTION; A SMALL MANOEUVRE BY
}

\author{
R. Foster MOORE \\ LONDON
}

I HAVE found the following manueuvre of considerable help in some cases of extraction and as such it seems worth recording. It seems improbable that it has not previously been employed, but I have never seen it described and I know of no one who has made use of it. It is a means by which buttonholing the iris in making the corneal section may be avoided.

It happens sometimes when cutting out that the iris falls over the knife and as the section is completed a portion of it is thus cut away. My habit is to incise the lens capsule with the knife on its passage across the anterior chamber, and I fancy the complication mentioned happens more often where this is done than when the capsule is incised by means of a cystotome on completion of the section. It is, of course, true that if one simply goes ahead, cutting through the iris deliberately, the cases usually do perfectly well, but there are two disadvantages. One is the pain felt by the patient and the second is that one has little or no control over the size and shape of the iridectomy. The resulting coloboma may be neat and satisfactory; it may, however, be large and irregular, and the pupillary portion may escape, necessitating its being dealt with separately before the lens can be extracted.

In many cases the wrapping of the iris over the knife can be avoided by carrying the point of the knife inwards and upwards at one sweep, so that almost the whole of the section is made by the belly of the knife and very little of it by the heel end of the blade; sometimes the whole of the section, and usually the greater part of it, can be completed by one sweep inwards and upwards of this kind, and the iris, which has shown a tendency to bulge over the edge, slips under it in a satisfying manner. This, of course, is a well-known manoeuvre and it is one I always make use of. Some surgeons lift the knife forwards and so get the iris to slip under it, but in some cases in spite of either of these devices it will get in the way.

If in such a case a repositor is taken in the other hand, right or left as the case may be, whilst the knife is in position, it will be found that by a stroking movement of the repositor over that part of the cornea which overlies the blade, the iris can be expressed from between the blade and the cornea, and made to slip under the knife, and so the section completed without damage to the iris. I have done this on many occasions and have very seldom found it to fail, even where it looked as if it were impossible to avoid buttonholing. 